\title{
Design and simulation of 5kW BLDC motor with half-buried permanent magnets using an existing stator body
}

\author{
Budi Azhari, Pudji Irasari, Puji Widianto \\ Research Center for Electrical Power and Mechatronics, Indonesian Institute of Sciences (LIPI), Bandung-Indonesia
}

\begin{tabular}{l} 
Article Info \\
\hline Article history: \\
Received Jun 3, 2021 \\
Revised Sep 8, 2021 \\
Accepted Sep 15, 2021 \\
\hline
\end{tabular}

\section{Keywords:}

BLDC motor

Cogging torque

Flux distribution

Half-buried magnets

Torque-speed characteristics

\begin{abstract}
This paper proposes a design of a $5 \mathrm{~kW}, 100$ volts brushless direct current (BLDC) motor using an existing stator connected to an inverter and equipped with Hall sensors. The stator is a radial flux motor-type with 54 slots positioned at the outer side of the machine. In this case, the design is focused on the rotor components and winding configuration. However, the inverter aspects are also taken into account. At the same time, it considers the expected outputs: voltage, power, speed; and some limitations: maximum current and flux density. Finite element magnetic-based simulation is performed to extract the magnetic flux distribution, and analytical calculations are then conducted to obtain the output values and characteristics. The results show the BLDC motor at nominal speed produces $5.1 \mathrm{~kW}$ output power with $122.34 \mathrm{~V}$ voltages, $97.09 \%$ efficiency, and torque of $32.82 \mathrm{Nm}$. The maximum torque and rotation speeds are $51.39 \mathrm{Nm}$ and 4,150 rpm respectively, while the peak-to-peak cogging force is $1.35 \mathrm{Nm}$. It can be concluded that the BLDC motor has a good performance and is compatible with the connected inverter.
\end{abstract}

This is an open access article under the CC BY-SA license.

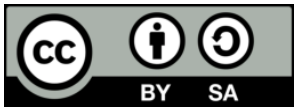

\section{Corresponding Author:}

Budi Azhari

Research Center for Electrical Power and Mechatronics

Indonesian Institute of Sciences

154D/21 Sangkuriang st, Coblong, Bandung-West Java 40135, Indonesia

Email: budi.azhari19@gmail.com

\section{INTRODUCTION}

Recently, the brushless DC (BLDC) permanent magnet motor has been used in many fields, for example in industrial machines, medical appliances, robotics, also for currently growing trend: electric vehicles (EVs) [1]-[4]. It is renowned for its excellent properties: simpler construction, relatively small in size and weight, high efficiency, high torque density, good dynamic response, low noise, and simple maintenance [5]-[10]. As an actuator, the BLDC motor has characteristics that basically combine the advantages of DC brushed motor and alternating current (AC) synchronous motor and at the same time eliminate their main drawbacks. Because the brushed DC motor suffers mechanical losses from the use of brushes and commutators, the BLDC motor avoids their presence by using an inverter to convert the input DC-current into a frequency-controlled AC wave. Furthermore, the inverting process employs electronic switches whose states' arrangement can be set to determine the resulted AC wave's frequency [11]. Therefore, a wider range of speed can be obtained along with a higher torque compared to the AC synchronous motor or the induction motor [12].

Physically, the BLDC motor has three main parts: the stator, the rotor, and the electronic components. The stator usually has a similar design as the DC brushed motor's, with some windings to generate synchronous flux [13]. Meanwhile, the rotor has several poles of permanent magnet that will be locked to the current-conducting winding to make a rotation. The number of the windings and the poles 
generally define the type and the parameter of the motor; also determine the electrical as well as the mechanical outputs. Because the motor operates with inverted DC voltage, the frequency of the resulted AC wave will influence its motion. Here, The BLDC motor performs electronic commutation by using solid-state components, instead of a mechanical commutator like the one in the conventional DC motor.

For designing the BLDC motor, the model can either be approached from a synchronous motor [14] or be derived from a common brushed DC motor [15]-[17]. Nowadays, the BLDC motor can also be designed as a slotted machine to optimize the air gap flux density and to achieve higher power density [12], or as a slotless one, as it can simplify its structure and minimize resulted cogging torque [13]. Nonetheless, the design process of the BLDC motor needs the desired outputs to be set at the beginning of the process [18]. From those pieces of information, the settings and dimensions of the BLDC components can be determined. There will be a challenge for designing a specific BLDC motor with certain output values if a certain motor part has existed.

In this paper, a $5 \mathrm{~kW}, 100$ volts BLDC motor design is proposed, but by utilizing an existing stator body. The provided stator was previously used for an asynchronous motor. It has multi slots but no coil yet. Hence, the rotor and the stator winding will be configured altogether. Similar studies were previously conducted by [19], [20], but they do not consider the inverter aspects. In this paper, the dimensions of the rotor components, the winding arrangement, as well as the inverter settings are determined adapting to properties and dimensions of the available stator. They also consider some output parameters, including expected terminal voltage, output power, and rotation speed; also aware of several limitations: maximum current and flux density. Simulations using finite element magnetic-based software are performed to extract the magnetic distribution, so analytical calculations can be conducted later to obtain the output values, and characteristics of the motor. From the research, the presented design process that covers the whole components of the BLDC motor and uses an existing asynchronous motor's stator can be reviewed or applied for the next researches.

\section{DESIGN OF BLDC MOTOR}

In this paper, the design of the BLDC motor consists of three main parts: the existing stator body, the motion controller to be regulated, and the rotor as well as the winding configuration to be designed. The first part will be explained, while the later configurations will be discussed subsequently.

\subsection{The existing stator design of the BLDC motor}

The existing stator body with fixed dimensions is shown in Figure 1. It is a radial flux motor-type with a cylindrical shape. An axial hollow present at the middle, parallel to the normal of the circular face. Meanwhile, the detailed dimensions are tabulated in Table 1. Given the available stator structure, it will be positioned as the outer part of the BLDC motor, while the rotor in the inner part will be designed.

From Figure 1, the existing stator is composed of yoke and slots-teeth regions. The yoke is formed from sheets of silicon steel material; with a thickness of $0.5 \mathrm{~mm}$ each. The magnetization curve of this material (50H1300-type) is presented in Figure 2. In this matter, the use of ferromagnetic material for the yoke aims to minimize the magnetic reluctance along the flux passage. Meanwhile, the laminations are arranged axially (or parallel to $z$-axis according to Figure 1 to minimize the eddy current loss. To fix the lamination sheets, they are bolted on six spots at the sheets' edges. The slots and teeth are in the inner part, with each amount 54 units. Furthermore, every tooth makes salient at its inner end. This topology is useful to reduce the teeth' reluctance and to minimize cogging torque [21], [22], hence improve the rotation smoothness.

Next, the basic model of the BLDC motor is to be stated based on the stator design. Since the number of the slot is known, it can be considered to determine the number of the winding and the pole pair. Generally, the higher the number, the torque and the iron loss will be higher, while the lesser number will make higher speed [23]. Other considerations may also be put into the table, including the manufacturing difficulties and costs. In this case, the 4 poles- 6 windings model of the BLDC motor is chosen. Considering the existing structure, the 54 stator slots will be divided into 6 groups of slots. They will be allocated for 6 winding sections of 3 phases. Each section is supported by 9 slots, thus the of slots per pole per phase $(q)$ is.

$$
q=\frac{S_{S}}{2 p m}
$$

Meanwhile, the span of the pole is [24]

$$
\operatorname{span}=I N T\left[\frac{s_{s}}{2 p}\right]
$$


$S_{s}$ is the number of slots, $2 p$ is the pole section number, and $m$ is the number of all phases.

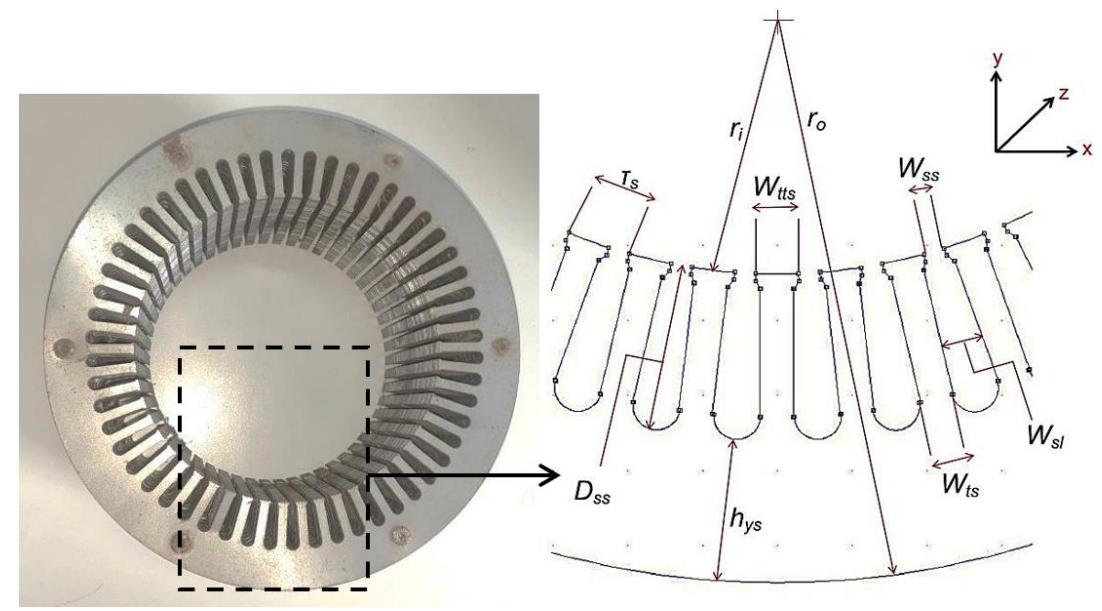

Figure 1. Design of the existing stator

Table 1. Dimension of the existing stator parts

\begin{tabular}{lcc}
\multicolumn{1}{c}{ Part, symbol } & Dimension & Unit \\
\hline Number of slot, $S_{\mathrm{s}}$ & 54 & units \\
Inner radius, $r_{i}$ & 0.0738 & $\mathrm{~m}$ \\
Inner diameter, $D_{i}$ & 0.1476 & $\mathrm{~m}$ \\
Outer radius, $r_{\mathrm{o}}$ & 0.1150 & $\mathrm{~m}$ \\
Outer diameter, $D_{\mathrm{o}}$ & 0.2300 & $\mathrm{~m}$ \\
Axial length, $l_{\mathrm{ax}}$ & 0.1030 & $\mathrm{~m}$ \\
Yoke thickness, $h_{\mathrm{ys}}$ & 0.0190 & $\mathrm{~m}$ \\
Slot opening width, $W_{\mathrm{ss}}$ & 0.00288 & $\mathrm{~m}$ \\
Salient width, $W_{\mathrm{tts}}$ & 0.00571 & $\mathrm{~m}$ \\
Tooth width, $W_{\mathrm{ts}}$ & 0.0045 & $\mathrm{~m}$ \\
Slot width, $W_{\mathrm{sl}}$ & 0.0056 & $\mathrm{~m}$ \\
Slot pitch, $\tau_{\mathrm{s}}$ & 0.0086 & $\mathrm{~m}$ \\
Slot depth, $D_{\mathrm{ss}}$ & 0.0200 & $\mathrm{~m}$ \\
Slot area, $a_{s}$ & 109.9 & $\mathrm{~mm}$ \\
\hline
\end{tabular}

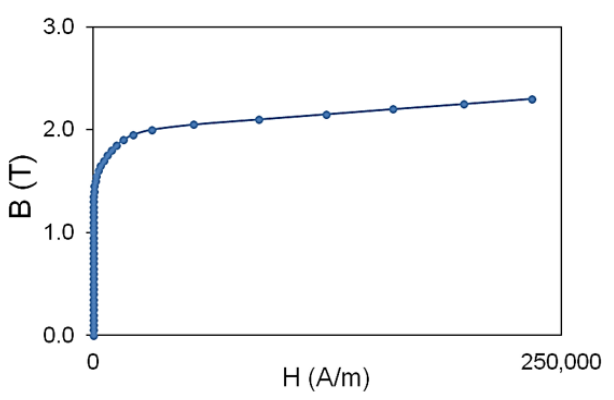

Figure 2. Magnetization curve of stator's silicon steel

\subsection{The BLDC controller topology}

To make the BLDC motion controllable, first, three Hall sensors are placed on the stator (Figure 3 (a)), to detect the rotor position. Next, the input DC voltage source supplying the three-phase windings should be first connected to an inverter. Here, 6 MOSFETs will be employed in a full-wave bridge inverter circuit (Figure 3 (b)). The MOSFETs will play a role as the switches. The states of the MOSFETs are regulated based on the Hall sensors' output to determine the movement of the rotor. When a switch is closed, DC input current will flow, and vice versa. As the states of 'closed' and 'open' occur sequentially under a certain period, square wave current signals will be formed. As presented in the circuit (Figure 3 (b)), the signals flow to the stator windings, which are connected in a star configuration. The current that flows in a certain phase winding will generate magnetic flux which flows to the rotor. The magnetic interactions between the phase winding's flux and the rotor poles will lock the poles and rotate the rotor. The rotating direction can be set based on the order of the flowing current to the phase windings, while the rotating speed can be regulated based on the state's period or the switching frequency.

In this case, the setting of the Hall sensors, the respective MOSFETs' states, and the resulted current flow among the phase windings are presented in Table 2. One Hall sensor changes its state for every $60^{\circ}$ electrical cycle, so it requires 6 stages to complete one Hall sensor cycle. The flow direction between the windings depends on the combination of the two conducting MOSFETs. Meanwhile, the generated square wave signal flows to all phases are shown in Figure 3 (c). Each phase is conducting current for a $120^{\circ}$ electrical cycle, with two phases will deliver current altogether for every conducting period (every $60^{\circ}$ electrical cycle). 


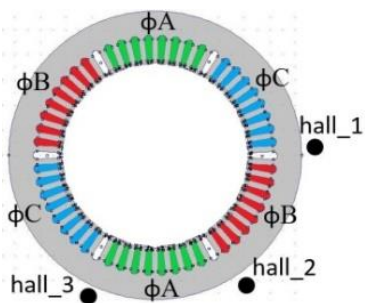

(a)

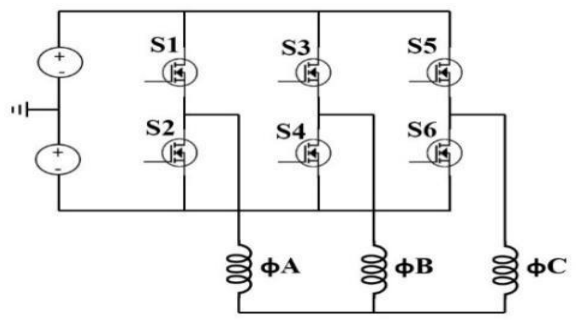

(b)

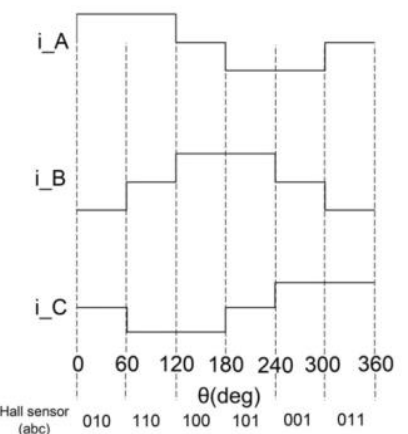

(C)

Figure 3. These figures are; (a) Hall sensors placement among six winding sections, (b) the full-wave bridge inverter circuit, (c) the resulted square waves in one complete electrical cycle, $\theta$ (the below numbers are the states of the Hall sensors 1,2, and 3 respectively)

Table 2. MOSFETs setting and resulted current flow

\begin{tabular}{ccccccccccc}
\hline \multicolumn{4}{c}{ Hall sensor } & \multicolumn{1}{c}{ MOSFETs' state } & \multicolumn{4}{c}{ Current flow } \\
1 & 2 & 3 & S1 & S2 & S3 & S4 & S5 & S6 & From phase & To phase \\
\hline 0 & 1 & 0 & 1 & 0 & 0 & 1 & 0 & 0 & A & B \\
1 & 1 & 0 & 1 & 0 & 0 & 0 & 0 & 1 & A & C \\
1 & 0 & 0 & 0 & 0 & 1 & 0 & 0 & 1 & B & C \\
1 & 0 & 1 & 0 & 1 & 1 & 0 & 0 & 0 & B & A \\
0 & 0 & 1 & 0 & 1 & 0 & 0 & 1 & 0 & C & A \\
0 & 1 & 1 & 0 & 0 & 0 & 1 & 1 & 0 & C & B \\
\hline
\end{tabular}

\subsection{Rotor and winding configurations of the BLDC motor}

The 4-poles rotor is configured to produce a sufficient amount of magnetic flux, which is proportional to the output voltage, power, and maximum torque. Under the operation of $120^{\circ}$ square wave signals, the flux generated in the no-load condition is.

$$
\begin{aligned}
& \varphi_{s q}=a_{i(s q)} \tau_{p} l_{a x} B_{p m}, \\
& a_{i(s q)}=\frac{\tau_{p m}}{\tau_{p}}=\frac{B_{a v}}{B_{p m}}
\end{aligned}
$$

$\varphi_{s q}$ is the resulted flux under the square wave signal $(\mathrm{Wb}), \tau_{p}$ and $\tau_{p m}$ are circular pole pitch $(\mathrm{m})$ and pole length (m) respectively, $l_{a x}$ is the axial length of the stator $(\mathrm{m}), B_{a v}$ and $B_{p m}$ show the average flux density and magnet's flux density, all in tesla. In this design, the value of $a_{i}$ under square wave signal is equal to the value under sinusoidal mode. The ratio between the two modes is $1 / k_{f}$, where.

$$
k_{f}=\frac{4}{\pi} \sin \left(\frac{a_{i} \pi}{2}\right)
$$

From (3) and (4), the dimensions of the magnets will determine the resulted flux.

The generated magnetic flux results in magnetic interaction that will lock the poles to certain phase windings. It will also result in back-electromotive force (back EMF), whose value is affected by the resulted flux and the winding configuration [25].

$$
\begin{aligned}
& E_{b}=c_{E, s q} \varphi_{s q} n_{s}, \\
& c_{E, s q}=8 p N_{p h} k_{w 1}, \\
& k_{w 1}=k_{d} k_{p} k_{s}
\end{aligned}
$$

In (6)-(8), $E_{b}$ is one phase back EMF (V), $c_{E, s q}$ is a coefficient of configuration, $n_{s}$ is the rated speed of rotation (rpm), $N_{p h}$ is the number of turns per phase, and $k_{w l}$ is winding factor in fundamental harmonics. Furthermore, $k_{d}$ is distribution factor, $k_{p}$ is pole shortening factor, and $k_{s}$ represents pole skewing factor.

The flux flows from the poles to stator teeth and stator yoke through the air gap, and back to rotor yoke and suitable poles. While the resulted magnetic flux is arranged to meet the expected output, the flux

Design and simulation of $5 \mathrm{~kW}$ BLDC motor with half-buried permanent magnets using an ... (Budi Azhari) 
density in both yokes and the stator teeth should be kept below $2 \mathrm{~T}$ [26] to avoid the saturation phase (based on the magnetization curve in Figure 2). The equations of the flux density in the respective parts are.

$$
\begin{aligned}
B_{Y S} & =\frac{\varphi_{s q}}{2 h_{y s} l_{\text {ax }} f_{\text {lam }}}, \\
B_{T S} & =\frac{B_{p m} \tau_{s}}{w_{t s} f_{\text {lam }}}, \\
B_{Y R} & =\frac{\varphi_{s q}}{2 h_{y r} l_{\text {lax }} f_{\text {lam }}},
\end{aligned}
$$

$B_{Y S}, B_{T S}$, and $B_{Y R}$ are flux density in the stator yoke, the stator tooth, and the rotor yoke successively (all in tesla). Meanwhile, $f_{\text {lam }}$ is the lamination factor of the respective yoke, $h_{y s}$ and $h_{y r}$ are the thickness of stator and rotor yokes $(\mathrm{m})$, while $w_{t s}$ is the stator teeth width $(\mathrm{m})$. Based on (9)-(11), the rotor yoke thickness should be carefully set, by considering the dimensions of the existing stator's yoke and teeth. Another to be determined parameter is winding configuration. Based on (6)-(8), the number of the stator turn is related to the resulted back-EMF. However, it is also affected by the maximum armature current [27], which depends on the current density and the inverter signal mode.

$$
I_{a}=J_{a} a_{w}, I_{a(s q)}=\sqrt{\frac{3 l_{a}}{2}}
$$

$I_{a}$ is armature current (A), $J_{a}$ is the phase winding current density $\left(\mathrm{A} / \mathrm{m}^{2}\right), a_{w}$ is the conductor front area $\left(\mathrm{m}^{2}\right)$, and $I_{a(s q)}$ is the armature current for operation of $120^{\circ}$ square wave signal. The number of turns in a slot should not exceed the filling factor $\left(f f_{s}\right)$ of the slot. The cumulative winding dimension then also affects the phase winding resistance $(\Omega)$.

$$
\begin{aligned}
& N_{s} a_{w}=f f_{s} a_{s} \\
& R_{a}=\frac{\rho_{R} l_{w}}{a_{w}} .
\end{aligned}
$$

$N_{s}$ is the number of turns per slot and $a_{s}$ is the surface area of the slot $\left(\mathrm{m}^{2}\right)$. Meanwhile, $\rho_{R}$ is the specific resistance of the wire $(\Omega \mathrm{m})$ and $l_{w}$ is the wire length of the phase winding $(\mathrm{m})$.

When the bridge rectifier as in Figure 3 (b) is installed and energized, there will be two conducting phase windings for every conducting period. According to the formed circuit, the phase-to-phase instantaneous terminal voltage will be.

$$
v_{i n}=\left(e_{\phi 1}-e_{\phi 2}\right)+2 R_{a} i_{a}+2 X_{s} i_{a} .
$$

$v_{\text {in }}$ is the input voltage $(\mathrm{V})$ in the motor input terminal. Operation $\left(e_{\varphi 1}-e_{\varphi 2}\right)$ represents the line-to-line backEMF voltage (V) generated in the stator. Notation $i_{a}$ is the instantaneous armature current (A), while $X_{s}$ is the synchronous winding reactance $(\mathrm{H})$ which the value is obtained from the equations as shown in [28].

$$
\begin{aligned}
& X_{s d}=X_{l}+X_{m d}, X_{s q}=X_{l}+X_{m q}, \\
& X_{l}=4 \pi f \mu_{0} \frac{L_{i} N_{1}{ }^{2}}{p q}\left(\lambda_{s}+\frac{l_{1 e}}{L_{i}} \lambda_{e}+\lambda_{1 d}\right), \\
& X_{m d}=2 m f \mu_{0} \frac{k_{w 1} N_{1}}{p}\left(\frac{r_{p m_{-}{ }^{2}-r_{p m_{-}}{ }^{2}}}{g_{d}^{\prime}}\right) k_{f d}, \\
& X_{m q}=2 m f \mu_{0} \frac{k_{w 1} N_{1}}{p}\left(\frac{r_{p m_{-} o^{2}-r_{p m_{i}}{ }^{2}}}{g^{\prime} q}\right) k_{f q} .
\end{aligned}
$$

$X_{l}$ is leakage reactance $(\Omega)$, while $X_{m d}$ and $X_{m q}$ are mutual reactance according to $d q$-axis respectively. $\mu_{o}$ is air permeability $\left(4 \pi \times 10^{-7} \mathrm{H} / \mathrm{m}\right), L_{i}$ is the effective winding length in a radial direction $(\mathrm{m}), N_{l}$ is the number of series winding in one phase, $\lambda_{s}$ is slot leakage permeance, $\lambda_{e}$ is winding end's leakage permeance, $\lambda_{I d}$ is differential leakage flux permeance, $g^{\prime}{ }_{d}$ and $g_{q}^{\prime}$ is equivalent air gaps in $d q$-axis (m), while $r_{p m_{-} o}$ and $r_{p m_{-} i}$ are pole's outer and inner radius $(\mathrm{m})$. Furthermore, $k_{f d}$ and $k_{f q}$ are form factors according to $d q$-axis.

The electromagnetic power $\left(P_{\text {elm }}\right.$ in watt) is the output power of the BLDC motor. This and the torque of the motor are also affected by the magnetic flux (from the poles settings) and the armature current (based on the winding configuration). They can be calculated by using the equations. 


$$
\begin{aligned}
& P_{e l m}=e_{l l} I_{a(s q)}, e_{l l}=e_{\phi 1}-e_{\phi 2}, \\
& T_{I_{\_} n}=k_{T} I_{a(s q)}, k_{T}=\frac{c_{E, s q} \varphi_{s q}}{2 \pi} .
\end{aligned}
$$

$T_{I_{-} n}$ is the torque under nominal current $(\mathrm{Nm})$. Next, the torque characteristics give information about the torque-speed relation, especially the limit values that should be obeyed to produce optimum performance. It is closely related to the rotation speed, as described by the equations as shown in,

$$
n=n_{o}\left[1-\frac{I}{I_{o}}\right]=n_{o}\left[1-\frac{T}{T_{o}}\right] .
$$

$T_{o}$ is stall torque $(\mathrm{Nm})$, or the maximum torque that stops the rotation of the motor. $n_{o}$ and $I_{o}$ are no-load rotation speed (rpm) and no-load current (A). They can be calculated by using the equations as shown in,

$$
n_{o}=\frac{v_{\text {in }}}{c_{E, s q} \varphi_{s q}}, I_{o}=\frac{v_{\text {in }}}{R_{a}} .
$$

When the motor is energized, some losses will be dissipated, both electrically and mechanically. The copper loss $\left(P_{c u}\right)$ and the core loss $\left(P_{c}\right)$ are two dominant electrical losses, all are stated in watt. The core loss itself is the sum of hysteresis and eddy current loss. These electrical losses are affected by the armature current, the winding configuration, and the resulted maximum flux density. The values of all those losses can be calculated using the equations as shown in,

$$
\begin{aligned}
& P_{c u}=m_{a}\left(I_{a(s q)}\right)^{2} R_{a}, \\
& P_{c}=C_{h} f B_{p}{ }^{a+b B_{p}}+C_{e} f^{2} B_{p}{ }^{2} .
\end{aligned}
$$

Notation $m_{a}$ is the number of active phases during a conducting period, $C_{h}$ is hysteresis coefficient $=0.0025$ while $C_{e}$ is eddy current coefficient $=7.94 \times 10^{-5}$. Notations of $a$ and $b$ are constants that depend on the electric steel material that is used. In this case, the value of $a=1.8317$ and $b=0.0035$. Furthermore, $B_{p}$ is the resulted maximum flux density in the respective body ( $\mathrm{T})$.

Next, the mechanical loss $\left(P_{m}\right.$, in watt) also appears during the motor's work. When the rotor moves, there will be losses due to friction in bearing $\left(P_{b}\right.$, in watt) and air gap $\left(P_{\text {gap }}\right.$, in watt). The losses' values can be calculated using the following equations,

$$
\begin{aligned}
& P_{m}=P_{b}+P_{g a p}, \\
& P_{b}=k_{f b} m_{r} n_{s} \times 10^{-3}, \\
& P_{g a p}=2 D_{r}^{3} l_{a x} n_{s}^{3} \times 10^{-6} .
\end{aligned}
$$

$k_{f b}$ is bearing friction coefficient whose value ranges between 1-3, $m_{r}$ is the rotor total mass $(\mathrm{kg})$, and $D_{r}$ is the rotor outer diameter (m). From (26)-(28), the losses' values are also affected by the rotor dimension. Moreover, additional losses $\left(P_{a d d}\right.$ in watt) including loss from leakage flux in slots and leakage flux in windings also exist. In this case, the value of the remaining losses is approximated $20 \%$ of the core loss. Finally, the total loss $\left(P_{l_{-} t o t}\right.$ in watt) and the efficiency $(\eta$ in $\%)$ of the motor is.

$$
\begin{aligned}
& P_{l_{-} t o t}=P_{c u}+P_{c}+P_{b}+P_{g a p}+P_{a d d}, \\
& \eta=\frac{P_{\text {elm }}}{P_{\text {elm }}+P_{l_{-} t o t}} \times 100 .
\end{aligned}
$$

Another obstacle when rotating the rotor is the cogging torque phenomena. It is a fluctuating torque resulted from changing attractive forces between the rotor poles and the ferromagnetic stator body. The phenomenon will cause ripple during the rotation and if the force is quite strong, it will cause vibrations and noises [29]. Next, the starting torque needs to increase. The cogging torque is stated by the formula as shown in,

$$
T_{c}=-\frac{1}{2} \varphi^{2} \frac{d \Re}{d \theta_{a}}
$$


$R$ is the air gap reluctance $(\mathrm{At} / \mathrm{Wb})$ and $\theta_{a}$ is the rotor position during rotation (rad).

\section{DESIGN AND ANALYSIS METHOD}

The flowchart for the design and analysis process of the BLDC motor with an existing stator body is shown in Figure 4. After elaborating on the stator design (Figure 1 and Table 1), the rotor design and the winding configuration are determined. However, prior to that step, some parameters need to be stated as the design references. They are including the expected output values, the desired settings' values, and the limit values for some parameters. The references' values are listed in Table 3.

The design process is then conducted considering the references' values and using the analytical calculations of (1)-(31). The selected inverter configuration is taken into consideration. In (3)-(7), (9)-(12), (20), (21), and (23), (24), the generated square wave signals from the inverter affect the resulted dimensions and output values. The electronic switching configuration is also considered, as the resulted current and polarity among the winding phases at a certain time will determine the magnetic flux flow.

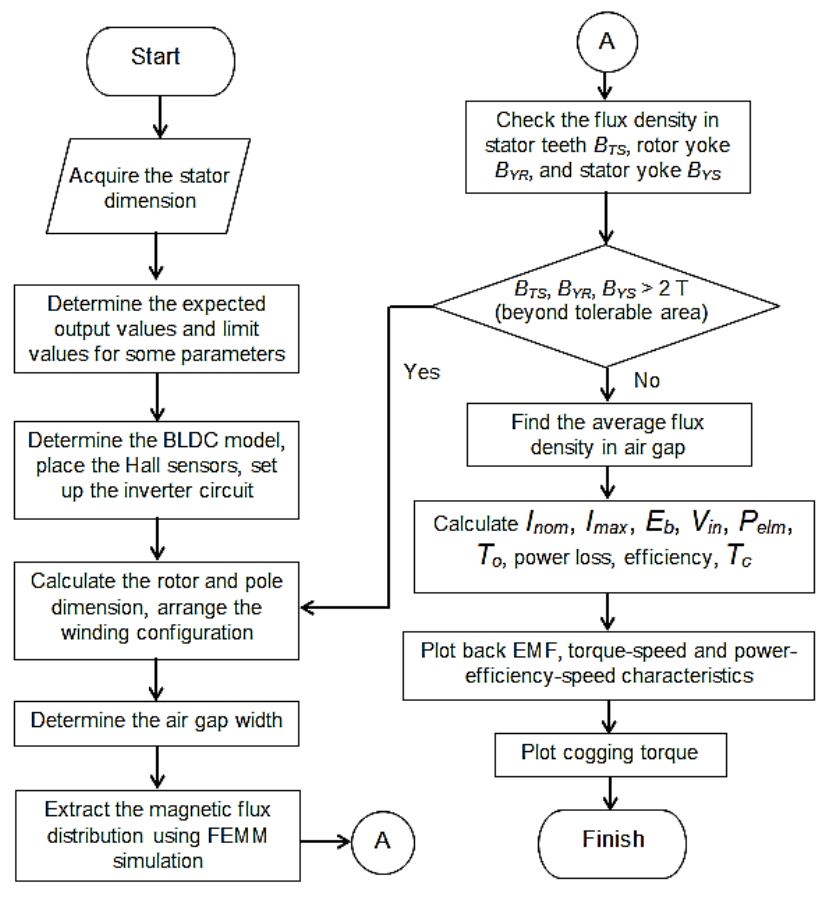

Table 3. References values for design

\begin{tabular}{ccc}
\hline Part, symbol & Dimension & Unit \\
\hline Inverter voltage, $V_{i n}$ & 100 & $\mathrm{~V}$ \\
Maximum inverter current, $I_{\max }$ & 120 & $\mathrm{~A}$ \\
Number of the pole, $2 p$ & 4 & - \\
Nominal frequency, $f$ & 50 & $\mathrm{~Hz}$ \\
Nominal rotation speed, $n_{s}$ & 1,500 & $\mathrm{rpm}$ \\
Number of phases, $m$ & 3 & - \\
Number of active phases during & 2 & - \\
conduction, $m_{a}$ & 0.02 & $\mathrm{~s}$ \\
Conduction period, $T_{c}$ & 100 & $\mathrm{~V}$ \\
Inverter voltage, $V_{i n}$ & &
\end{tabular}

Figure 4. Flowchart of the design, simulation, and analysis

After the design is complete, the magnetic flux distribution is extracted through finite element magnetic-based simulation using FEMM software under no current and nominal current conditions. The magneto-static principle is applied, in which the magnetic fields are treated as a time-invariant function. In this case, the flowing current that produces certain magnetic fields is fixed at a specific state, so that the magnetic parameters at that state can be extracted. To change the design condition (i.e., rotating the rotor) or the phases' current values, the state is updated, and the new parameters' values can be obtained again. Hence, to model time-variance progress, several different states are captured sequentially. In magneto-static mode, the relation between the magnetic field and the current density satisfies the following equations.

$$
\nabla \times \bar{H}=J ; \nabla \cdot \bar{B}=0
$$

$\boldsymbol{H}$ and $\boldsymbol{B}$ represent the vectors of the magnetic field $(\mathrm{A} / \mathrm{m})$ and flux density $(\mathrm{T})$. Relation between both parameters can be expressed in vector potential $\boldsymbol{A}$,

$$
\begin{aligned}
& \bar{B}=\mu_{r} \mu_{0} \bar{H}=\nabla \times \bar{A} \\
& \varphi_{t}=B_{t} a_{t}
\end{aligned}
$$


$\phi_{t}$ is the flux magnitude in a salient ( $\left.\mathrm{Wb}\right), B_{t}$ is the salient flux density (T), and $a_{t}$ is the tooth surface area $\left(\mathrm{m}^{2}\right)$. At this stage, it needs to be ensured that the flux densities in the stator and rotor do not exceed the maximum allowable value, otherwise the rotor and the winding need redesigning. To find the back-EMF, the flux linkage is gained from the circuit properties extracted through FEMM simulation. The value can be approached from the sum of the flux magnitudes in teeth which are covered by the respective phase coil.

$$
\lambda \approx N_{s} \sum_{i}^{\text {teeth_covered }} k_{i} B_{n i} a_{t}
$$

$\lambda$ is the flux linkage of a coil phase (Wb), $k$ is a coefficient. The back-EMF is then

$$
E_{b}=\frac{d \lambda}{d \theta_{a}} \frac{d \theta_{a}}{d t}
$$

$\theta_{a}$ is the angular position of the rotor ( $\left.\mathrm{rad}\right)$, and $d \theta_{d} / d t$ represents the nominal angular speed ( $\left.\mathrm{rad} / \mathrm{s}\right)$. From those values, several output parameters can then be calculated, including the line-to-line voltage, terminal voltage, electromagnetic power, dissipated losses, efficiency, as well as stall torque. The characteristics of torque and speed can also be plotted based on the calculations. Finally, the cogging force will be measured through the simulation for checking the smoothness during the rotor rotation.

\section{RESULTS AND DISCUSSION}

In this section, the resulted design of the rotor, as well as the winding configuration, will be described first. Then the output of the BLDC motor will be explained subsequently.

\subsection{Rotor design and winding configuration}

The resulted design of the rotor is shown in Figure 5, while the dimensions of its all parts are tabulated in Table 4. In the rotor, each pole section consists of five segments of the magnet; all are made of $\mathrm{NdFeB}$ material with $\mathrm{N} 45 \mathrm{H}$-type which has a remanence of $1.32 \mathrm{~T}$ and a maximum operating temperature of $120{ }^{\circ} \mathrm{C}$. Every magnet is separated one another by the rotor yoke column. The magnetic polarities of the two opposite pole sections are the same. Hence, two opposite pole sections have the "North" poles in the outer part and the inner part for the other opposite ones. Furthermore, the magnets are "half-buried". Their outer surfaces still face the stator and are in contact with the air gap. However, the main bodies are fixed inside the rotor yoke, while the edges of the outer magnets' surface are held and locked by parts of the rotor yoke.

The use of several magnet segments is to divide the magnetic flux flow to the rotor yoke and to increase the overall surface area of the magnet. Therefore, the maximum flux density can be lowered. Then the hysteresis and eddy current losses can also be reduced. Meanwhile, the total flux flow to the stator can still be kept, since the additional air gap from the height of the clippers at the edges of the permanent magnets is relatively small. Furthermore, the division of each pole into several magnet segments will more distribute the attractive force (with the stator body) along the longer pole arc. The use of the half-buried permanent magnet configuration with edges' clippers is to more easily fix the magnets' position into the rotor.

On the other hand, the winding employs a spiral-type configuration as shown in Figure 6 (a). Each phase's windings fill certain stator slot numbers Figure 6 (b) in a certain way. Every slot is divided into two layers: the inner and outer layers. Each layer is filled with different phase windings Figure 6 (c). In Figure 6 (c), the positive sign means the wire is coming out and the negative means it is coming into. As only eight slots in each section are filled, there will be six empty slots in total, out of 54 slots. The configuration is chosen by evenly distributing the six empty slots to reduce cogging torque and to avoid unbalanced magnetic pulls. However, such configuration causes the winding to shorten, shortening four slots to give $k_{w}=0.853$. From these arrangements, the value of $k_{d}, k_{p}$, and $k_{s}$ can also be obtained. They are recorded in Table 4.

The resulted rotor movement based on its configuration and the inverter input is shown in Figure 7. The arrows in the poles show their magnetic orientations. Meanwhile, the sequence of the flowing phase current from Figure 7 (a) to Figure 7 (f) is based on Figure 3 (c) and Table 2. For instance, in Figure 7 (a) the electrical cycle is from 0 to 60 degrees. The current is flowing from phase A to phase B (Table 2). Thus, the positive current flows in phase winding $\mathrm{A}$, whereas the negative one flows in phase winding $\mathrm{B}$. According to the configuration shown in Figure 6 (c), the current in the phases of A and B will generate certain magnetic fields in certain directions. In Figure 7 (a), the arrows in the stator show the direction of the fields, and the letters show which phase produces them. The same analysis can be carried out for Figure 7 (b)-(f). Based on the 4 poles- 6 windings configuration and the order of the conducting phases, one pole pair needs one complete electrical cycle to make a complete rotation. Thus, every pole section needs two complete electrical cycles to make a full mechanical rotation. 

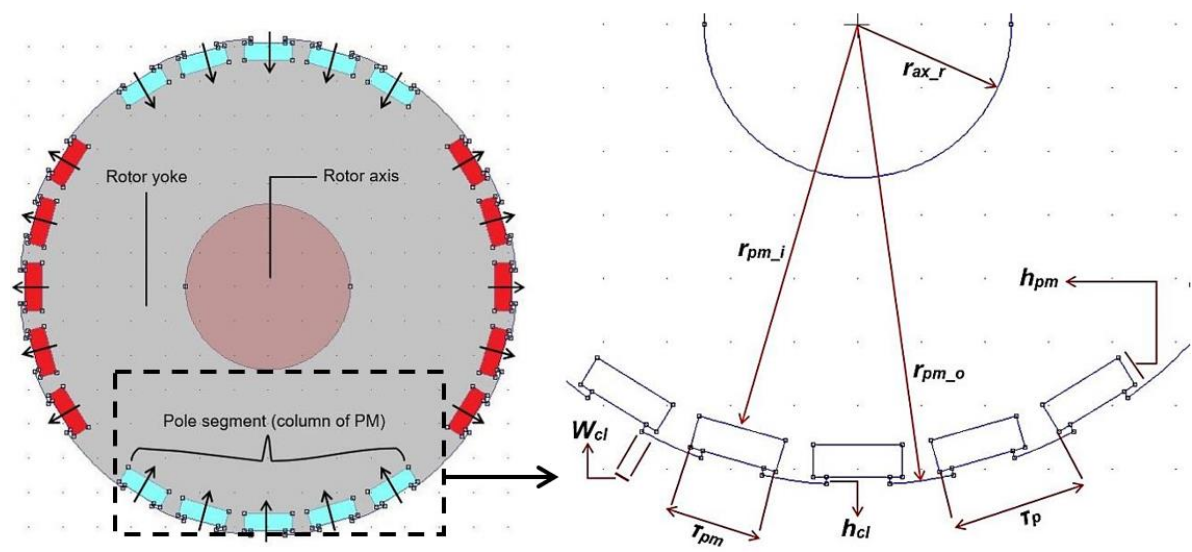

Figure 5. Resulted rotor design, with the arrows in the poles' magnets (left) show their magnetic orientations

Table 4. Resulted rotor dimensions and winding parameters

\begin{tabular}{lcc}
\hline \multicolumn{1}{c}{ Part, symbol } & Dimension & Unit \\
\hline Radius of the rotor axis, $r_{a x_{-} r}$ & 24.15 & $\mathrm{~mm}$ \\
Pole outer radius, $r_{p m_{\_} o}$ & 72.5 & $\mathrm{~mm}$ \\
Pole inner radius, $r_{p m_{-} i}$ & 61.5 & $\mathrm{~mm}$ \\
Pole pitch, $\tau_{p}$ & 20.2 & $\mathrm{~mm}$ \\
PM length, $\tau_{p m}$ & 14 & $\mathrm{~mm}$ \\
PM thickness, $h_{p m}$ & 5 & $\mathrm{~mm}$ \\
Height of the PM edges' clipper, $h_{c l}$ & 1.2 & $\mathrm{~mm}$ \\
Width of the PM edges' clipper, $W_{c l}$ & 2 & $\mathrm{~mm}$ \\
Wire diameter, $D_{w}$ & 3.7 & $\mathrm{~mm}$ \\
Turn per phase, $N_{p h}$ & 64 & - \\
Coil per slot, $N_{s}$ & 2 & - \\
Wire per coil, $N_{c}$ & 2 & - \\
Current density, $J$ & 3.2 & $\mathrm{~A} / \mathrm{mm}^{2}$ \\
Distribution factor, $k_{d}$ & 0.964 & - \\
Pole shortening factor, $k_{p}$ & 0.885 & - \\
Pole skewing factor, $k_{s}$ & 1 & - \\
Winding factor, $k_{w l}$ & 0.853 & - \\
\hline
\end{tabular}

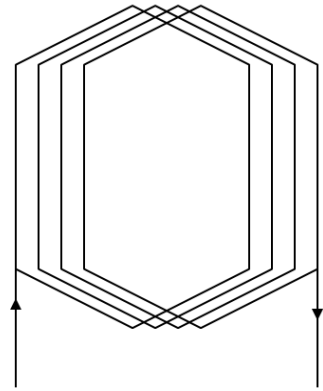

(a)

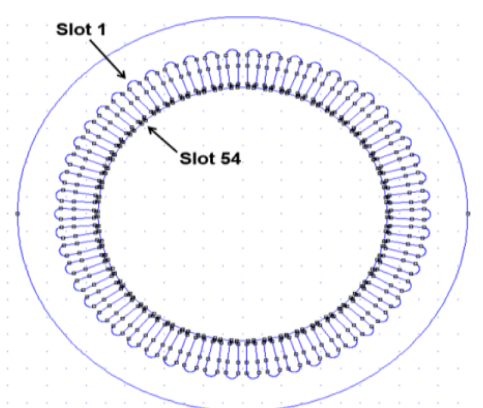

(b)

\begin{tabular}{|c|c|c|c|c|c|c|c|c|c|c|c|c|c|c|c|c|c|c|c|c|c|c|c|c|c|c|}
\hline 1 & 2 & 3 & 4 & 5 & 6 & 7 & 8 & 9 & 10 & 11 & 12 & 13 & 14 & 15 & 16 & 17 & 18 & 19 & 20 & 21 & 22 & 23 & 24 & 25 & 26 & 27 \\
\hline 28 & 29 & 30 & 31 & 32 & 33 & 34 & 35 & 36 & 37 & 38 & 39 & 40 & 41 & 42 & 43 & 44 & 45 & 46 & 47 & 48 & 49 & 50 & 51 & 52 & 53 & 54 \\
\hline$+A$ & $+A$ & $+A$ & $+A$ & $+C$ & $+C$ & $+C$ & $+C$ & & $-A$ & $-A$ & $-A$ & $-A$ & $-A$ & $-A$ & $-A$ & $-A$ & & $-C$ & $-C$ & $-C$ & $-C$ & $+A$ & $+A$ & $+A$ & $+A$ & \\
\hline$-B$ & $-B$ & $-B$ & $-B$ & $-B$ & $-B$ & $-B$ & $-B$ & & $+C$ & $+C$ & $+C$ & $+C$ & $+B$ & $+B$ & $+B$ & $+B$ & & $+B$ & $+B$ & $+B$ & $+B$ & $-C$ & $-C$ & $-C$ & $-C$ & \\
\hline
\end{tabular}

(c)

Figure 6. These figures are, (a) winding configuration, (b) slot numbering, (c) winding arrangement based on the numbering 


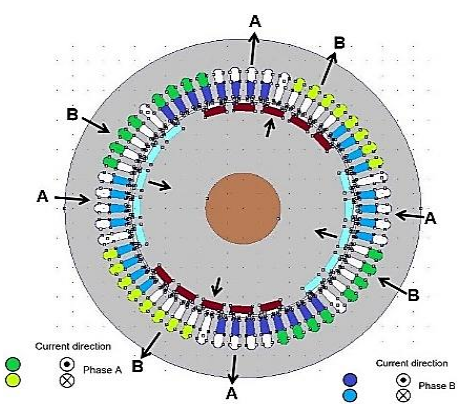

(a)

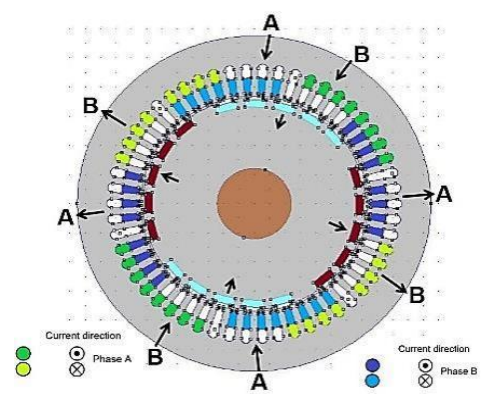

(d)

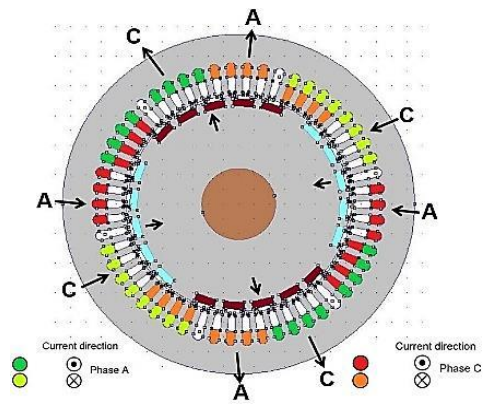

(b)

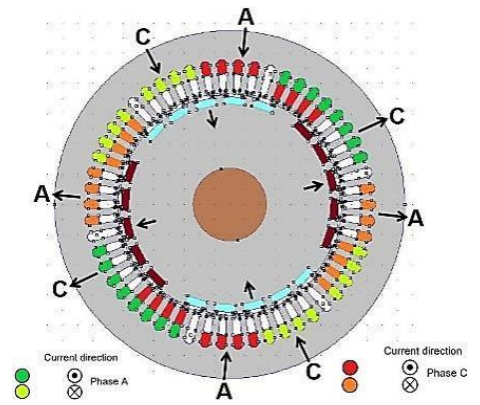

(e)

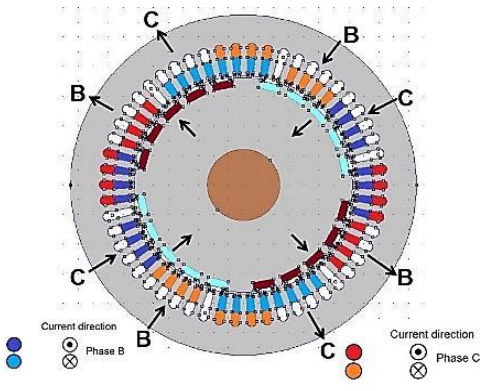

(c)

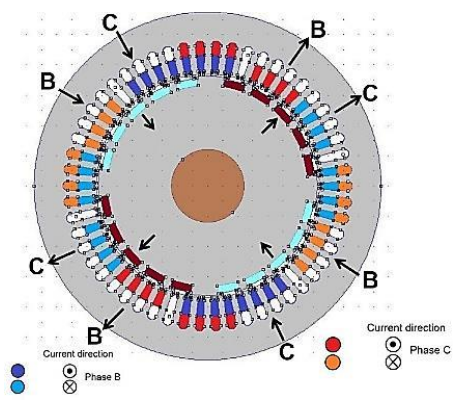

(f)

Figure 7. Rotor position sequence during the rotation on the electrical cycle of, (a) $60^{\circ}$, (b) $120^{\circ}$, (c) $180^{\circ}$, (d) $240^{\circ}$, (e) $300^{\circ}$, (f) $360^{\circ}$

\subsection{Output of the BLDC motor}

The flux distributions of the resulted motor under no current and nominal current conditions are shown in Figure 8. In no current condition (Figure 8 (left)), the flux density is concentrated around the magnets as the magnetic flux sources. However, when nominal current is injected, the windings will generate reverse magnetic flux that opposes the poles' magnetic flux. In that situation, the flux density in the stator yoke will increase, especially in the stator yoke area which is passed by magnetic flux flowing between two opposite polarity poles (Figure 8 (right)). Regarding the value, the maximum flux density reaches slightly above $2 \mathrm{~T}$, but is still in the tolerable saturation range of the stator's 50H1300 material [26].

The air gap flux density in a stator tooth fluctuates as the rotor rotates. Its value depends on its relative position with respect to the rotor. Figure 9 (left) shows the graph of the flux density in a tooth when it is passed by the rotor. The resulted five-wave peaks show the amount of magnet segment in each pole section. The flux and flux density reach the maximum values as the tooth directly faces a magnet segment. When nominal phase current is injected, there are increases in negative values of the flux densities. In this case, the positive flux direction is coming out of the rotor's poles. The increases are the result of the stator phase windings generating opposite magnetic flux in opposite directions with respect to the poles' magnetic flux. The negative flux will also reduce the resultant flux magnitude. From Figure 9 (left), the average flux density in no current condition is $0.4713 \mathrm{~T}$, while under nominal current it decreases to $0.2810 \mathrm{~T}$.

The resulted flux magnitude will determine the back EMF as well as the output torque. The first term is proportional to the required input voltage to produce certain amounts of torque and power. In Figure 9 (right), the back-EMFs for all phases are presented. For each phase, the graph forms a trapezoidal shape as in the usual BLDC motor [30], with the width of its peak is $120^{\circ}$ electrical cycle, and transition from zero voltage to the peak is about $60^{\circ}$.

Table 5 then tabulates the outputs of the BLDC motor at nominal speed. The output power is 5.1 $\mathrm{kW}$, which slightly exceeds the desired output of $5 \mathrm{~kW}$. The copper loss accounts for the largest loss proportion suffered by the BLDC motor, while the estimated additional loss has the smallest value. From the resulted losses, the efficiency of the motor at the nominal speed is obtained at $97.09 \%$. Meanwhile, the maximum torque or the stall torque is $51.39 \mathrm{Nm}$ and the rated torque is $32.82 \mathrm{Nm}$.

The output torque-speed characteristic is further shown in Figure 10 (a). The torque is linearly opposite to the rotation speed. In this design, the maximum allowable speed is $4,150 \mathrm{rpm}$, in which the motor's torque is down to zero. In Figure 10 (b), the relation between the output power and efficiency towards the rotation speed is shown. The maximum power of the motor, 5,584.25 W occurs at 2,100 rpm but is followed by the drop of efficiency to $96.63 \%$. After that point, the motor's output power and efficiency

Design and simulation of 5kW BLDC motor with half-buried permanent magnets using an ... (Budi Azhari) 
continue to decrease as both core loss and mechanical loss continue to increase at high rotation. Meanwhile, the cogging torque graph is presented in Figure 11. The peak-to-peak range of the torque is $1.35 \mathrm{Nm}(0.43$ $\mathrm{Nm}$ to $-0.92 \mathrm{Nm}$ ), which is relatively small $(4.1 \%$ of the rated torque). Thus, the resulted torques are expected to not making significant noise and ripple during rotor movement.

From the results, all aspects that contribute to the work of the BLDC motor have been presented and analyzed. The winding and rotor configurations are suitable for the inverter setting. A similar study has been partially conducted [19]. This research completes the analysis by involving the inverter components. The resulted flux density is still within the range of tolerance. Meanwhile, the output voltage and output power have reached the expected values. The torque and rotation speed show sufficient values and suit the targeted results. Furthermore, the peak-to-peak cogging torque is relatively insignificant to disturb the rotation of the rotor. Hence the designed BLDC motor in overall shows a relatively good performance. This design process of BLDC motor from an existing stator can then be reviewed and applied in similar cases in other researches. Further improvement for the next research can be performed by selecting optimum materials with smaller reluctance. Hence the output voltage and power can be maximized.

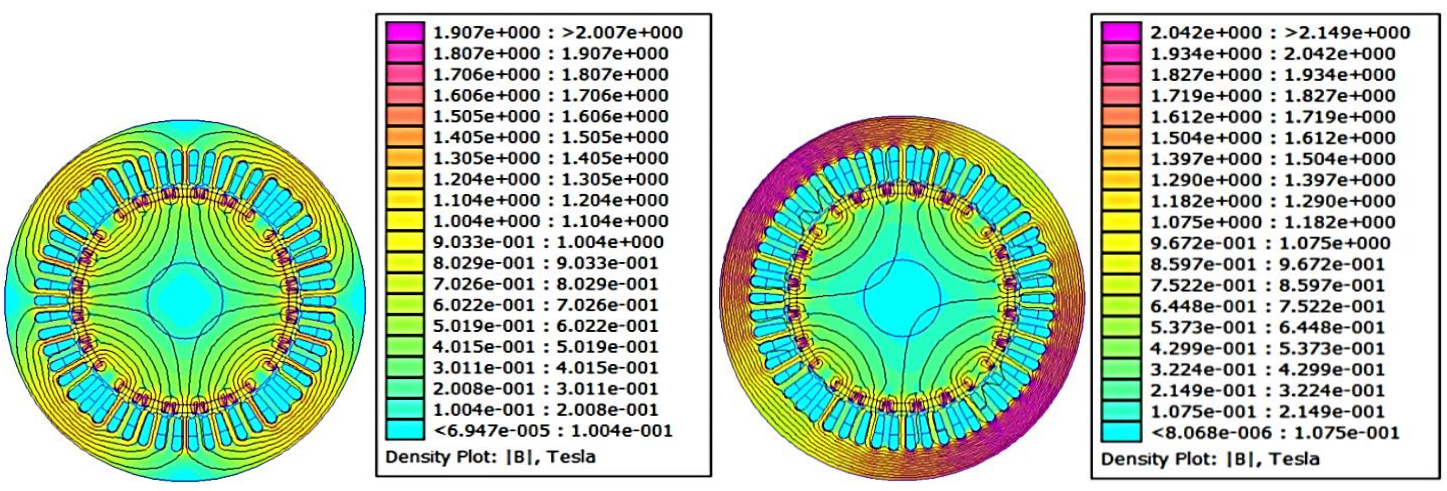

Figure 8. Flux distribution of the LPMG design under no current (left) and nominal current (right)
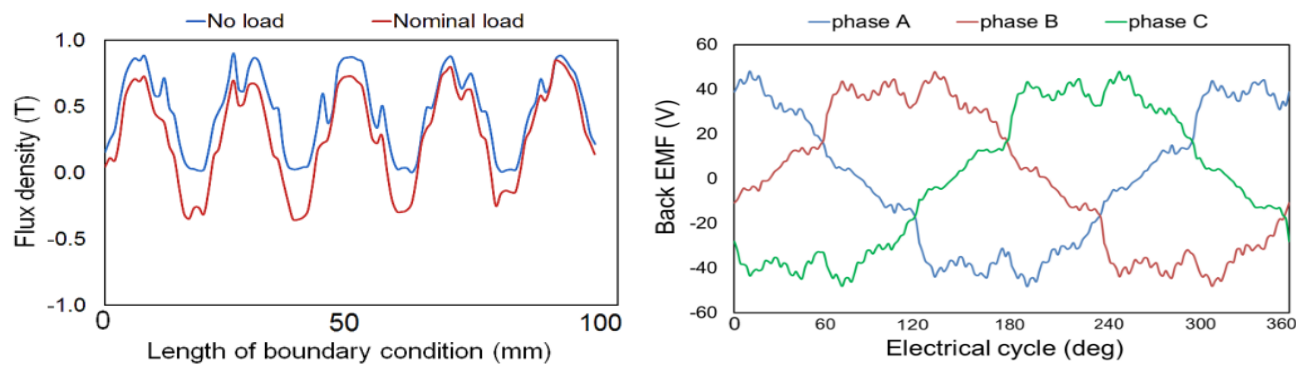

Figure 9. Flux densities in a tooth under no current and nominal current (left) and back-EMF of all phases (right)

Table 5. Output values of the BLDC motor

\begin{tabular}{lcc}
\hline \multicolumn{1}{c}{ Part, symbol } & Dimension & Unit \\
\hline Line-to-line back EMF, $e_{l l}$ & 122.34 & $\mathrm{~V}$ \\
The input voltage, $v_{i n}$ & 198.25 & $\mathrm{~V}$ \\
Armature current under square wave signal, $I_{a(s q)}$ & 42.14 & $\mathrm{~A}$ \\
Electromagnetic power, $P_{e l m}$ & $5,155.29$ & $\mathrm{~W}$ \\
Copper loss, $P_{c u}$ & 74.77 & $\mathrm{~W}$ \\
Core loss, $P_{c}$ & 33.75 & $\mathrm{~W}$ \\
Mechanical loss, $P_{m}$ & 39.51 & $\mathrm{~W}$ \\
Additional loss, $P_{a d d}$ & 6.75 & $\mathrm{~W}$ \\
Total loss, $P_{l}$ tot & 154.78 & $\mathrm{~W}$ \\
Rated torque, $T$ & 32.82 & $\mathrm{Nm}$ \\
Stall torque, $T_{o}$ & 51.39 & $\mathrm{Nm}$ \\
No-load current, $I_{o}$ & 65.98 & $\mathrm{~A}$ \\
No-load rotation speed, $n_{o}$ & 69.19 & $\mathrm{rps}$ \\
Efficiency, $\eta$ & 97.09 & $\%$ \\
\hline
\end{tabular}




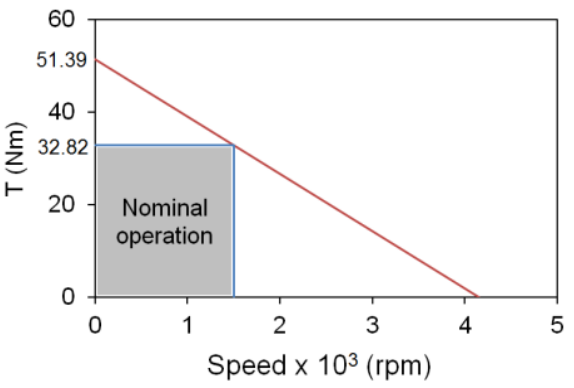

(a)

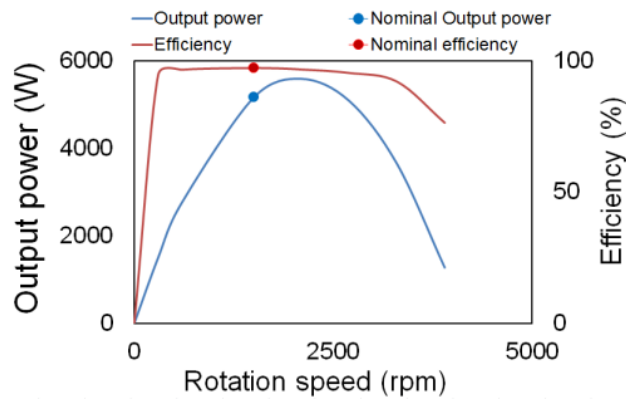

(b)

Figure 10. These figures are, (a) torque-speed characteristics, (b) graph of output power-efficiency towards rotation speed

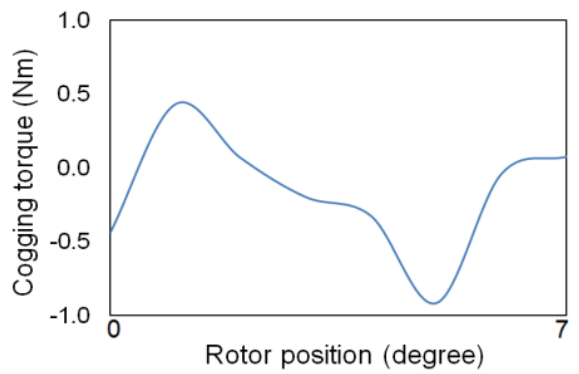

Figure 11. Cogging torque of the BLDC motor

\section{CONCLUSION}

A BLDC motor, connected to an inverter circuit and equipped with Hall sensors, has been designed based on an existing stator body. The motion converter and the rotor with half-buried permanent magnets are designed to adapt to the dimension and topology of the stator. Some desired outputs are stated, including expected voltage, output power, and rotation speed. Meanwhile, several limitations, including maximum current and flux density, are also considered. The flux distribution is extracted by using finite element magnetic-based software of FEMM, and it is found that the maximum flux density is still in the tolerable range. Analytical calculations show that: At nominal speed, the BLDC motor can produce acceptable results, which are $5.1 \mathrm{~kW}$ of output power with $122.34 \mathrm{~V}$ of voltage, $97.09 \%$ of efficiency, and $32.82 \mathrm{Nm}$ of rated torque; the maximum torque and rotation speed obtained from the torque-speed characteristics are $51.39 \mathrm{Nm}$ and 4,150 rpm, respectively; the cogging torque curve shows a relatively small peak-to-peak value of $1.35 \mathrm{Nm}$. The results conclude that the BLDC motor has a good performance and is compatible with the connected inverter. Next research can be performed by optimizing the materials used to minimize the reluctance.

\section{ACKNOWLEDGEMENTS}

The authors gratefully thank the Deputy of Engineering Science, Indonesian Institute of Sciences for the financial support under Electrical Vehicle project, number 26/A/DT/2021.

\section{REFERENCES}

[1] D. Potnuru, K. Alice Mary, and Ch. Sai Babu, "Experimental implementation of Flower Pollination Algorithm for speed controller of a BLDC motor," Ain Shams Engineering Journal, vol. 10, no. 2, pp. 287-295, June 2019, doi: 10.1016/j.asej.2018.07.005.

[2] Z. U. Bayrak and M. T. Gencoglu, "Application areas of fuel cells," 2013 International Conference on Renewable Energy Research and Applications (ICRERA), 2013, pp. 452-457, doi: 10.1109/ICRERA.2013.6749798.

[3] H. Seol, D. Kang, H. Jun, J. Lim, and J. Lee, "Design of Winding Changeable BLDC Motor Considering Demagnetization in Winding Change Section," IEEE Transactions on Magnetics, vol. 53, no. 11, pp. 1-5, Nov. 2017, doi: 10.1109/TMAG.2017.2695890.

[4] J. Feng, K. Liu, and Q. Wang, "Scheme based on buck-converter with three-phase H-bridge combinations for highspeed BLDC motors in aerospace applications," IET Electric Power Applications, vol. 12, no. 3, pp. 405-414, March 2018, doi: 10.1049/iet-epa.2017.0615. 
[5] M. Ridwan, D. C. Riawan, and H. Suryoatmojo, "Particle swarm optimization-based BLDC motor speed controller with response speed consideration," 2017 International Seminar on Intelligent Technology and Its Applications (ISITIA), 2017, pp. 193-198, doi: 10.1109/ISITIA.2017.8124079.

[6] M. Kumar and K. Chaursiya, "Position control of brushless DC motor using harmony search algorithm optimization technique," 2017 Int. conf. of Elect., Comm. and Aerospace Tech. (ICECA), 2017, pp. 754-757.

[7] B. A. kumar, C. Kamal, D. Amudhavalli, and T. Thyagarajan, "Reformed Stator Design of BLDC Motor for Cogging Torque Minimization Using Finite Element Analysis," 2018 4th International Conference on Electrical Energy Systems (ICEES), 2018, pp. 481-484, doi: 10.1109/ICEES.2018.8442389.

[8] U. Nagalingam, B. Mahadevan, K. Vijayarajan, and A. P. Loganathan, "Design optimization for cogging torque mitigation in brushless DC motor using multi-objective particle swarm optimization algorithm," COMPEL: The International Journal for Computation and Mathematics in Electrical and Electronic Engineering, vol. 34, no. 4, pp. 1302-1318, July 2015, doi: 10.1108/COMPEL-07-2014-0162.

[9] B. Alsayid, W. A. Salah, and Y. Alawneh, "Modelling of sensored speed control of BLDC motor using MATLAB/SIMULINK," International Journal of Electrical and Computer Engineering (IJECE), vol. 9, no. 5, p. 3333, October 2019, doi: 10.11591/ijece.v9i5.pp3333-3343.

[10] M. S. Raja and B. Geethalakshmi, "Modified Rotor Material for Minimization of Torque Ripple for Interior Permanent Magnet BLDC motor," Materials Today: Proceedings, vol. 5, no. 2, pp. 3639-3647, 2018, doi: 10.1016/j.matpr.2017.11.614.

[11] A. A. Obed, A. L. Saleh, and A. K. Kadhim, "Speed performance evaluation of BLDC motor based ondynamic wavelet neural network and PSO algorithm," International Journal of Power Electronics and Drive Systems (IJPEDS), vol. 10, no. 4, pp. 1742-1750, December 2018, doi: 10.11591/ijpeds.v10.i4.pp1742-1750.

[12] M. Khelifa, M. Mordjaoui, and A. Medoued, "An inverse problem methodology for design and optimization of an interior permanent magnetic BLDC motor," International Journal of Hydrogen Energy, vol. 42, no. 28, pp. 1773317740, July 2017, doi: 10.1016/j.ijhydene.2017.02.017.

[13] A. Shabanian, A. A. P. Tousiwas, M. Pourmandi, A. Khormali, and A. Ataei, "Optimization of brushless direct current motor design using an intelligent technique," ISA Transactions, vol. 57, pp. 311-321, July 2015, doi: 10.1016/j.isatra.2015.03.005.

[14] I. Anshory, I. Robandi, and Wirawan, "Monitoring and optimization of speed settings for Brushless Direct Current (BLDC) using Particle Swarm Optimization (PSO)," 2016 IEEE Region 10 Symposium (TENSYMP), 2016, pp. 243-248, doi: 10.1109/TENCONSpring.2016.7519412.

[15] D. Kumpanya, S. Thaiparnat, and D. Puangdownreong, "Parameter Identification of BLDC Motor Model Via Metaheuristic Optimization Techniques," Procedia Manufacturing, vol. 4, pp. 322-327, 2015, doi: 10.1016/j.promfg.2015.11.047.

[16] V. K. S. Patel and A. K. Pandey, "Modeling and Performance Analysis of PID Controlled BLDC Motor and Different Schemes of PWM Controlled BLDC Motor," International Journal of Scientific and Research Publications, vol. 3, no. 4, pp. 1-14, 2013.

[17] R. Palanisamy, R. Sahasrabuddhe, M. K. Hiteshkumar, and J. A. Puranik, "A new energy regeneration system for A BLDC motor driven electric vehicle," International Journal of Electrical and Computer Engineering (IJECE), vol. 11, no. 4, pp. 2986-2993, August 2021, doi: 10.11591/ijece.v11i4.pp2986-2993.

[18] Y. B. A. Apatya, A. Subiantoro, and F. Yusivar, "Design and prototyping of 3-phase BLDC motor," 2017 15th International Conference on Quality in Research (QiR): International Symposium on Electrical and Computer Engineering, 2017, pp. 209-214, doi: 10.1109/QIR.2017.8168483.

[19] M. Y. Marusina, A. A. Silaev, and D. A. Nevmerzhitsky, "Method of Converting an Induction Motor to a Permanent Magnet Synchronous Motor (Ls-Pmsm) with Linear Starting Using FEA for Mechatronic Systems," 2019 International Conference "Quality Management, Transport and Information Security, Information Technologies" (IT\&QM\&IS), 2019, pp. 356-358, doi: 10.1109/ITQMIS.2019.8928320.

[20] Y. K. Chin and J. Soulard, "A Theoretical Study on Permanent Magnetsynchronous Motors for Electric Vehicles," in 6th International Power Engineering Conference (IPEC) 2003, Singapore, Nov. 2003, pp. 435-440.

[21] F. D. Wijaya, B. Azhari, and H. Stephanus, "Optimum Permanent Magnets Configuration in Flat-Quasi Linear Permanent Magnet Generators," International Journal of Electrical and Computer Engineering (IJECE), vol. 6, no. 6, pp. 2589-2602, December 2016, doi: 10.11591/ijece.v6i6.11966.

[22] H. Arof, A. M. Eid, and K. M. Nor, "Cogging force reduction using special magnet design for tubular permanent magnet linear generators," 39th Int. Uni. Power Eng. Conf., 2004. UPEC 2004, vol. 1, pp. 523-527, 2004.

[23] J. S. Park and K.-D. Lee, "Design and Implementation of BLDC Motor with Integrated Drive Circuit," International Journal of Power Electronics and Drive Systems (IJPEDS), vol. 8, no. 3, pp. 1109-1116, September 2017, doi: 10.11591/ijpeds.v8.i3.pp1109-1116.

[24] I. Boldea and S. A. Nasar, "The Induction Machine Handbook," CRC Press, p. 968, 2010.

[25] J. F. Gieras, "Permanent magnet motor technology: design and applications," 3rd ed. Boca Raton: CRC Press, 2010.

[26] P. Irasari, H. S. Alam, and M. Kasim, "Magnetic Simulation and Analysis of Radial Flux Permanent Magnet Generator using Finite Element Method," Journal of Mechatronics, Electrical Power, and Vehicular Technology, vol. 3, no. 1, pp. 23-30, July 2012, doi: 10.14203/j.mev.2012.v3.23-30.

[27] M. Yazdani-Asrami, M. Alipour, and S. A. Gholamian, "Optimal ECO-Design of Permanent Magnet Brushless DC Motor Using Modified Tabu Search Optimizer and Finite Element Analysis," Journal of Magnetics, vol. 20, no. 2, pp. 161-165, June 2015, doi: 10.4283/JMAG.2015.20.2.161. 
[28] P. Irasari, P. Widiyanto, and M. F. Hikmawan, "Desain dan Simulasi GMP Fluks Aksial Berbasis Dimensi Magnet Permanen Komersil," ELKOMIKA: Jurnal Teknik Energi Elektrik, Teknik Telekomunikasi, \& Teknik Elektronika, vol. 8, no. 3, p. 602, August 2020, doi: 10.26760/elkomika.v8i3.602.

[29] C. Kamal, T. Thyagarajan, M. Selvakumari and D. Kalpana, "Cogging torque minimization in brushless DC motor using PSO and GA based optimization," 2017 Trends in Industrial Measurement and Automation (TIMA), 2017, pp. 1-5, doi: 10.1109/TIMA.2017.8064815.

[30] M. A. Ibrahim, A. Kh. Mahmood, and N. S. Sultan, "Optimal PID controller of a brushless DC motor using genetic algorithm," International Journal of Power Electronics and Drive Systems (IJPEDS), vol. 10, no. 2, pp. 822-830, June 2019, doi: 10.11591/ijpeds.v10.i2.pp822-830.

\section{BIOGRAPHIES OF AUTHORS}
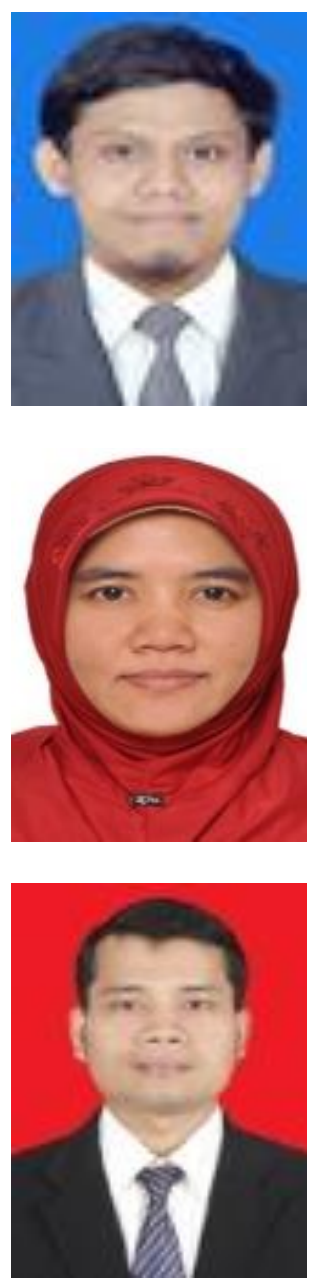

Budi Azhari received the B. Eng. and M. Eng degrees in Electrical Engineering both from the Department of Electrical Engineering and Information Technology, Universitas Gadjah Mada in 2016 and 2017 respectively. His research topics are focused on the design and analysis of the electric machine, mainly for renewable energy conversion. He is currently working as a researcher on the Electrical Vehicle Project at Research Center for Electrical Power and Mechatronics, Indonesian Institute of Sciences. (Scopus: 57221973939, ORCID: 0000-00030094-8902)

Pudji Irasari completed B.Eng. degree in Universitas Brawijaya in 1994 and M.Sc. degree at Oldenburg University, Germany in 2003. Her research interests including analysis of renewable energy conversion, electric machine design, and electrical power system assessment. She is currently conducting a project on water turbines for electricity generation at Research Center for Electrical Power and Mechatronics, Indonesian Institute of Sciences, collaborate with Institut Teknologi Bandung, Indonesia. (Scopus: 56087989100)

Puji Widiyanto received his B. Eng. and M. Eng. degrees both in Mechanical Engineering, first in STT Mandala and later in Institute Technology Bandung. Having focused his research on the structure and mechanical design of electrical machines, he is now working as a researcher at the Research Center for Electrical Power and Mechatronics, the Indonesian Institute of Sciences. Currently, he is conducting a project on water turbines for electricity generation, collaborates with Institut Teknologi Bandung, Indonesia (Scopus: 56966777600) 